\title{
Estimating the water needed to end the drought or reduce the drought severity in the Carpathian region
}

\author{
T. Antofie, G. Naumann, J. Spinoni, and J. Vogt \\ European Commission, Joint Research Centre, Institute for Environment and Sustainability (IES), \\ Climate Risk Management Unit, Ispra, Italy \\ Correspondence to: T. Antofie (tiberiuantofie@yahoo.com)
}

Received: 6 December 2013 - Published in Hydrol. Earth Syst. Sci. Discuss.: 5 February 2014

Revised: 6 November 2014 - Accepted: 27 November 2014 - Published: 12 January 2015

\begin{abstract}
A drought severity climatology for the Carpathian region has been produced using the self-calibrating Palmer Drought Severity Index (Sc-PDSI) for the period 19612010. Using the Sc-PDSI and the assumptions of the Palmer drought model (PDM) the precipitation required for drought termination (when Sc-PDSI reaches - 0.5) and amelioration (when Sc-PDSI reaches -2.0) are computed for periods of 1 , 3 , and 6 months. We discuss the reduction of the uncertainty in the determination of the beginning and ending of drought conditions, and provide a quantitative measure of the probability that any drought could be ameliorated or terminated. We present how the spatial variability of the amount of water needed for drought recovery and the climatological probability of receiving that amount of water is determined by the local conditions against the general climate characteristics of a small area such as the Carpathian region. Regionally, the Pannonian Basin, the Transylvanian Plateau and the external Carpathian foothills and plains in the southern and eastern part of the region require the highest quantity of precipitation to recover from a drought while having the lowest climatological probabilities for such amounts of rainfall. High precipitation amounts over the northern and northwest part of the region result in higher soil moisture supplies and higher climatological probabilities to end a given drought event. Moreover, the succession and/or predominance of particular types of general atmospheric circulation patterns produce a seasonal cycle and inter-annual variability of precipitation that is quantitatively reflected in the excess of precipitation that is above normal required for drought recovery. Overall, the results of this study provide an overview on the chances of recovery from a drought period with moderate or severe
\end{abstract}

drought and present information useful in decision making in water and drought management.

\section{Introduction}

Drought is one of the most far-reaching natural and socioeconomic disasters (WMO/UNCCD/FAO/UNW-DPC, 2013). Traditionally, the acknowledgement and attempts to manage droughts were mostly orientated towards crisis management, while little attention has been given to proactive drought risk management. More recently, European as well as international policies and initiatives have highlighted the need for a more proactive, risk-based management of droughts. Examples are the requirement for the set-up of River Basin Management Plans, including Drought Management Plans under the European Water Framework Directive (WFD), the High-Level Meeting on National Drought Policies (HMNDP, http://www.hmndp.org), or the Integrated Drought Management Programme (IDMP, http://www.droughtmanagement. info) established by the World Meteorological Organization (WMO) and the Global Water Partnership (GWP) in 2013 .

An essential element in risk management is the reduction of drought impacts (i.e., mitigation) based on an assessment of the cost of damages associated with droughts as compared to the costs for efficient early warning and preparedness, including the adaptation to climate change. Drought as a natural hazard has been the subject of a great number of studies, focusing on the definition of drought and the development of drought indicators (e.g., Palmer, 1965; McKee et al., 1993; Wells et al., 2004; Vicente-Serrano et al., 2010) as well as on 
drought assessment and monitoring (e.g., Briffa et al., 1994; Guttman, 1998; Lloyd-Hughes and Saunders 2002; Dai et al., 2004; van der Schrier et al. 2006; Dai, 2011). However, little attention was given to the analysis of probabilities that a given drought (and its impacts) could be ameliorated or terminated through adequate rainfalls. The number of studies addressing the drought recovery topic is few (Karl et al., $1986,1987)$ and articles focused on drought as a natural hazard (Wilhite, 2000; Wilhite and Buchanan, 2005) as well as reports on drought management and monitoring (e.g., WMO, 2006; IPCC, 2007; ISDR, 2007), address the subject only in a general manner.

This paper provides a quantitative measure of the probability that any drought could be ameliorated or terminated over some defined period of time using the Palmer drought model (PDM) (Karl et al., 1987) with its assumptions and limitations. The study was partially implemented in the framework of the CARPATCLIM project (http://www.carpatclim-eu. org). Within this project, a consortium of meteorological services and environmental institutes of nine countries of the region joined forces with the purpose of improving the availability and accessibility of quality-controlled meteorological and climatological data. Based on the CARPATCLIM daily and monthly gridded data $\left(0.1^{\circ} \times 0.1^{\circ}\right.$ resolution for the 1961-2010 period), a series of indicators (self-calibrating Palmer Drought Severity Index - Sc-PDSI, Standardized Precipitation-Evapotranspiration Index - SPEI, Standardized Precipitation Index - SPI, Reconnaissance Drought Indicator - RDI, and Palfai Drought Index - PADI) were computed with the purpose of defining the climate characteristics of the region. Among them the Sc-PDSI was selected due to its use in measuring the intensity and severity of drought events in Europe (van der Schrier et al., 2006, 2007). Also, it was selected due to its ability to quantify the impact of droughts on a wide range of economic sectors (it serves as a meteorological, hydrological and agricultural drought index, Karl, 1983; Karl and Knight, 1985), using a physical based model build on a complex soil water budget system. As opposed to the PDSI, the Sc-PDSI is more spatially comparable across regions using fixed parameters related to the soil/surface characteristics at each location. In addition, it can be used (following the assumptions of the Palmer drought model) to assess the chances of drought recovery. Despite its importance, quantifying drought recovery has not been examined in the Carpathian region yet. Moreover, agriculture is a major economic sector in the Carpathian region (UNEP/DEWA, 2007). The main crops in the region are winter wheat, maize and potatoes (UNEP/DEWA, 2007), which are highly vulnerable to droughts throughout the whole year. Therefore information on ending or ameliorating droughts such as climatological probability that the droughts could be recovered and the seasonal analysis of drought occurrence could be useful in decisions concerning water and agricultural resources management.
The Sc-PDSI is a drought indicator based on the principles of balance between moisture supply and demand. A series of articles have pointed out the assumptions, strengths and weaknesses of the Palmer drought model along with details on calculation procedures (Alley, 1984; Karl, 1987, 1986a, b; Wells et al., 2004; van der Schrier et al., 2006 ). The PDSI or modified versions of PDSI have been used to quantify drought as a recurrent extreme climate event both at continental (Europe, North America) and global level (Dai et al., 2004; Dai, 1998, 2011; Wells et al., 2004; van der Schrier et al., 2006, 2007). By changing the standardization used by Palmer (1965), which was based on data from the US, Wells et al. (2004) proposed the Sc-PDSI and it was recognized as an improvement of the original PDSI (Dai, 2011). PDSI was developed with the intention of measuring the departure of soil moisture from the normal conditions, using a hydrological accounting system. Different from PDSI other drought indicators are based on past statistics of certain climate variables which often include only precipitation (Dai, 2011) and assumes that droughts are directly controlled by the temporal variability of the precipitation. Recent studies have confirmed the importance of the effect of other variables, such as temperature, on drought conditions. These studies (Williams et al., 2011; Martínez-Villalta et al., 2008; McGuire et al., 2010; Linares and Camarero, 2011) have shown that temperature rise affects the severity of the droughts and mainly the drought stress induced by heat waves on net primary production and tree mortality. For examples, the heat waves in Europe in 2003 and 2010 played extreme roles in influencing drought severity, which increased evapotranspiration and aggravated the drought severity (Rebetez et al., 2006). As a result - enhanced by precipitation shortage (Adams et al., 2009) - major decreasing in net primary production (Ciais et al., 2005) and high forest mortality occurred. This shows how drought stress - through increased evapotranspiration is induced, to a large degree, by the availability of soil moisture. Therefore, the use of drought indices which is based on soil water balance model, such as PDSI or modified versions as Sc-PDSI, is required in order to calculate current soil moisture conditions. Moreover, the statistical based drought indicators are normalized measures with respect to location and period, which makes the frequency of their severity classes climatologically consistent for any site (Heinrich and Gobiet, 2012), not being able to identify regions that are more "drought-prone" than others (Hayes et al., 1999). Therefore, PDSI has been used as it allows for comparison of drought frequency within different severity classes on different locations and it is suitable to account the drought under global warming conditions. Various aspects of the hydrological model, on which the PDSI is based on, are directly used in the calculation procedure of the precipitation required to recover from drought, which not only confers homogeneity but also offers means of validation of the obtained results.

Based on these considerations and using the assumptions of the Palmer drought model (PDM), the precipitation 


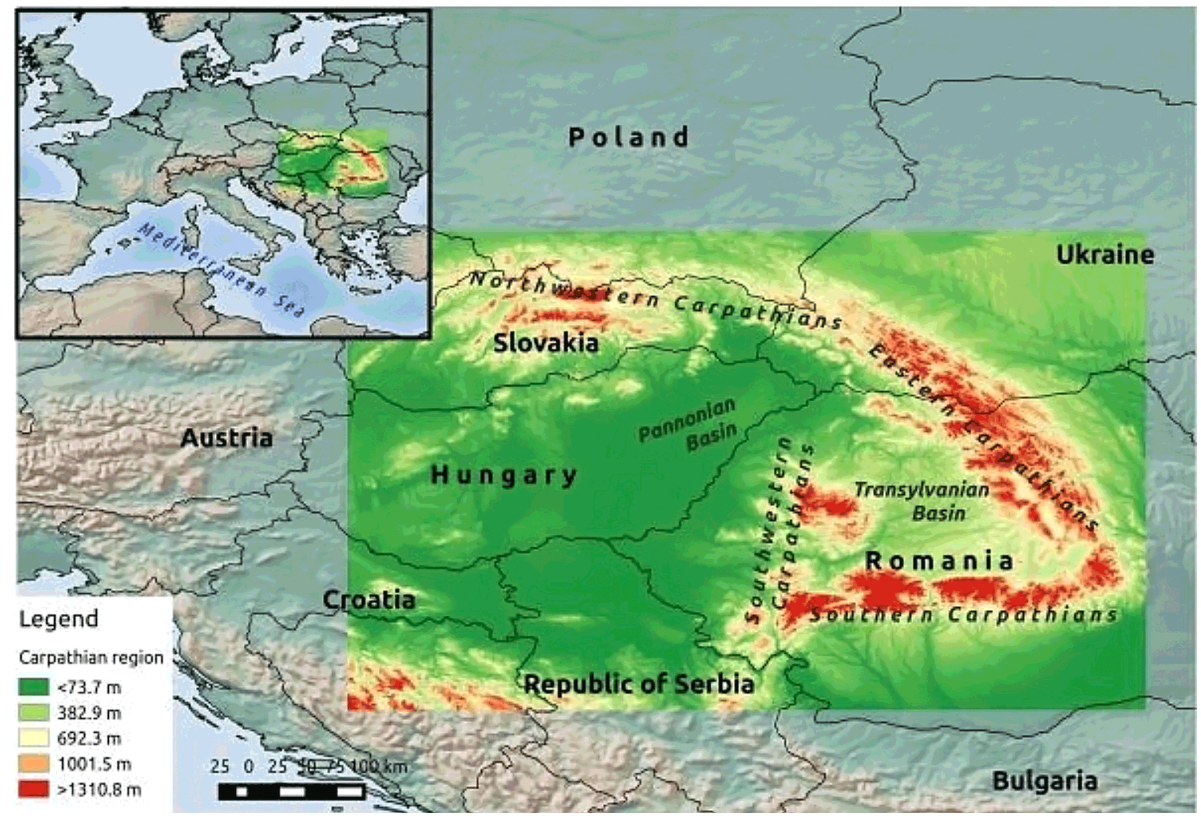

Figure 1. Carpathian region - geographical units.

needed to end or ameliorate a drought (in a 1-, 3-, or 6-month period) for different levels of severity (moderate when ScPDSI $\leq-2$, severe when Sc-PDSI $\leq-3$, extreme when ScPDSI $\leq-4$ ), and their climatological probability have been computed. A spatial and temporal analysis of these results is presented, including information on the deviation (\%) of the required precipitation from the normal annual rainfall cycle and an analysis of the months of the year with the highest/lowest probability for terminating a drought at different levels of severity.

\section{Data and methodology}

\subsection{Data}

The region covered by this study, depicted in Fig. 1, is centered on the Carpathian Mountains and the surrounding lowlands $\left(17-27^{\circ} \mathrm{E}, 44-50^{\circ} \mathrm{N}\right)$. Stretching across Central and Eastern Europe, the Carpathian Mountains spans over seven countries (in the studied region), starting from the Czech Republic, Slovakia and Poland in the northwest, then continuing east and southwards through Ukraine, Hungary, Romania and Serbia. The region also spans over parts of Croatia, Bosnia-Herzegovina, Bulgaria and Republic of Moldova. The Carpathian Mountains represent a prolongation of the Alps to the east and northeast, but their structure is less compact, and they are split up into a number of mountain blocks (with heights reaching over $2000 \mathrm{~m}$ in altitude) separated by basins (such as Pannonian and Transylvanian) and surrounded by lowlands. The Carpathian region receives polarcontinental air masses arriving from the east and northeast in the winter, while during other seasons, oceanic air masses from the west and also Mediterranean in the southern part (UNEP/DEWA, 2007). The calculation procedure for the water needed to recover from drought events is elaborated upon the Palmer drought model used to compute the Sc-PDSI. The computation of the Sc-PDSI (Wells et al., 2004) is carried out on monthly temporal scale and is based on the moisture demand and supply (water-balance model) and takes into account precipitation, evapotranspiration and soil moisture conditions. The basic input data are the following:

- Gridded monthly precipitation (from the CARPATCLIM project at $0.1^{\circ} \times 0.1^{\circ}$ spatial resolution for the 1961-2010 period),

- Gridded monthly mean surface air temperature (from the CARPATCLIM project $0.1^{\circ} \times 0.1^{\circ}$ resolution for the 1961-2010 period) used to compute Thornthwaite's potential evapotranspiration - PET, (Thornthwaite, 1948).

Temperature and precipitation gridded data have been interpolated within the CARPATCLIM project from qualitychecked, completed, homogenized and harmonized daily station data. Please see Spinoni et al. (2013) for a more detailed description.

- The available water holding capacity (AWC) of the soil is computed from the soil texture classes and soil profile depths in the European Soil Database (http://eusoils.jrc. ec.europa.eu/) and the Soil Geographical Database of Eurasia (Toth and Weynants, 2012). The AWC value for each grid cell, shown in Fig. 2, is assumed to be constant 


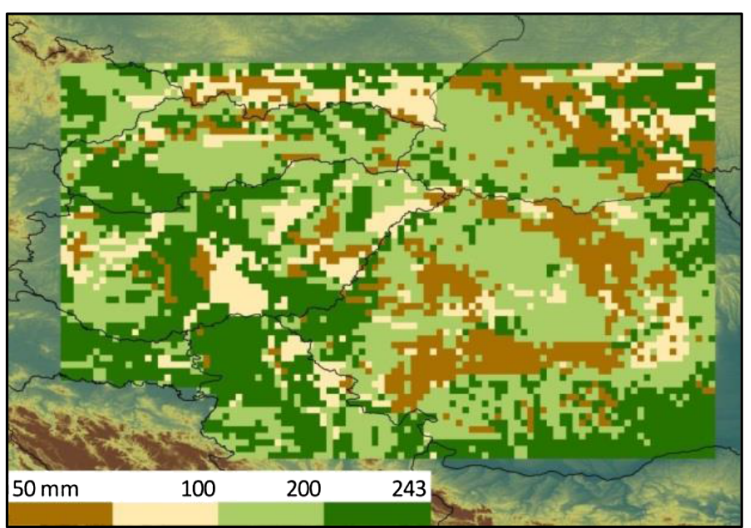

Figure 2. Available water holding capacity (AWC) of the soil (mm) in the Carpathian region.

over the considered period and calculated using the van Genuchten equation for which the parameters are obtained from the Hydraulic Properties of European Soils (HYPRES) pedotransfer class functions (based on the texture classes) (Wösten et al., 1999).

For the computation of the precipitation needed to recover from drought gridded data sets of CAFEC (climatically appropriate for existing conditions) precipitation (precipitation needed to maintain a normal soil moisture level), climate characteristic coefficient and the moisture anomaly index from the Palmer drought model for 1961-2010 period were used. A complete description of these variables is presented in Sect. 2.2.2

\subsection{Computation methodologies}

\subsubsection{Sc-PDSI computation}

Sc-PDSI is based on the Palmer Drought Severity Index (PDSI), first introduced by Palmer (1965), and modified by Wells et al. (2004) in order to allow a more accurate comparison of the index at different locations. ScPDSI measures the cumulative departure of moisture supply and demand from the normal conditions and is computed on monthly time scale. The supply in this model is the precipitation, the water demand is the potential evapotranspiration and the outputs are the actual evapotranspiration and runoff. Often discussed in other studies (e.g., Alley 1984; Karl, 1986a; Guttman et al., 1992; Weber and Nkemdirim, 1998; Wells et al., 2004; Dai et al., 2004; Vicente-Serrano et al., 2010) the strengths, weakness and differences of these two drought indicators will not be examined in this study. The major difference comes from the reduced frequency of extreme events of Sc-PDSI when compared with PDSI. This aspect is the result of the overall effect of the calibration based on the actual climatic characteristics of a given location that makes Sc-PDSI more consistent over diverse climatological regions.
The Sc-PDSI calculation procedure starts with the calculation of the monthly hydrological parameters of a rather complex soil water balance system: evapotranspiration, recharge, runoff, water loss from the soil and their potential values. The hydrological system is confined by the assumptions that the soil is split in two layers (with the upper soil layer holding $25.4 \mathrm{~mm}$ of water) and the saturation level (of both soil layers) is conditioned by the top layer, both on supply and demand.

The potential evapotranspiration (PET) is estimated following Thornthwaite (1948), while the other potential parameters are defined as follows: the potential recharge (PR) is the amount of moisture required to bring the soil moisture up to filed capacity (AWC less the total amount of moisture stored in both soil layers), the potential loss (PL) is the moisture that could be lost from the soil if precipitation is zero for the month and the potential runoff (PRO) is defined as total AWC less potential recharge (PR). The climatically appropriate for existing conditions (CAFEC) precipitation (or the precipitation needed to maintain a normal soil moisture level) is obtained by summing the monthly mean potential values which are previously scaled by their ratio with the monthly mean actual values.

The difference between monthly precipitation and CAFEC-precipitation, weighted by a local climate characteristic coefficient (an empirical derived normalization factor) results in Palmer moisture anomaly index (Palmer's ZIndex). A description of the modifications made to obtain Sc-PDSI is presented in Appendix A.

\subsubsection{Ending and ameliorating the drought}

The Sc-PDSI $i$ values and the assumptions of the Palmer drought model (PDM) were used for setting the theoretical basis of the calculation of precipitations needed to recover from the drought. Gridded data sets of CAFEC precipitation $(\hat{P})$, the climate characteristic coefficient $\left(K_{i}\right)$ and the moisture anomaly index $\left(Z_{i}\right)$ (from the Palmer drought model) for the 1961-2010 period are employed. The calculation starts by rewriting PDM's equation used to compute the moisture anomaly index $\left(Z_{i}\right)$, as follows:

$P_{i}=\left(\frac{Z_{i}}{K_{i}}\right)+\hat{P}_{i}$,

where $i$ denotes the months of the year, $P_{i}=$ precipitation needed to end or ameliorate the drought, $\hat{P}_{i}=$ CAFEC precipitation and $K_{i}=$ the coefficient of climate characteristic.

However, before being able to compute $P_{i}, Z_{i}$ has to be adapted to recovering drought conditions (end or ameliorate) and $\hat{P}_{i}$ has to be related with the Sc-PDSI ${ }_{i-1}$ (of the previous month) as CAFEC precipitation (with its soil water balance variables) cannot be computed until the end of the month. 


\section{The first step}

This represents the transformation of the moisture anomaly index $\left(Z_{i}\right)$ from the self-calibrated drought severity formula in Eq. (2) into the moisture anomaly index needed to end the drought $\left(Z_{\mathrm{e}}\right)$ and the moisture anomaly index needed to ameliorate the drought $\left(Z_{\mathrm{a}}\right)$.

Sc_PDSI $i_{i}=p$ Sc_PDSI $i_{-1}+q Z_{i}$,

where $q$ and $p$ are weighted factors.

From the PDSI severity classes (Palmer, 1965), adopted also for the Sc-PDSI (Table 1), it can be stated that a drought event ends when the Sc-PDSI increases above -0.5 . Therefore, when the Sc-PDSI $i$ in Eq. (2) is set to -0.5 and solving for $Z_{i}$ - which now should be mentioned as the moisture anomaly index needed to end the drought $\left(Z_{\mathrm{e}}\right)$ - the new formula becomes the following:

$Z_{\mathrm{e}}=\left(\frac{-0.5}{q}\right)-\left(\frac{p}{q} \mathrm{Sc} \_\right.$PDS $\left.I_{i-1}\right)$.

Considering the same severity classes, it can be assumed that a drought is ameliorated when the Sc-PDSI reaches a value of -2.0 . Applying the same hypothetical basis when trying to calculate the moisture anomaly index needed to ameliorate the drought $\left(Z_{\mathrm{a}}\right)$, the Sc-PDSI ${ }_{i}$ in Eq. (2) is set to -2.0 and the formula becomes the following:

$Z_{\mathrm{a}}=\left(\frac{-2.0}{q}\right)-\left(\frac{p}{q} \mathrm{Sc} \_\right.$PDSI $\left._{i-1}\right)$.

The weighted factors $q$ and $p$ are computed at all the locations (grid points) and they are specific for the dry spells. They are site-dependent which make the $Z_{\mathrm{a}}$ and $Z_{\mathrm{e}}$ unique for every grid point. Moreover, these two formulas can be computed not only for different values of Sc-PDSI ${ }_{i-1}$ but also for periods of time longer than a month. Once these simultaneous equations are solved, moisture anomaly indexes needed to end $\left(Z_{\mathrm{e}}\right)$ or ameliorate $\left(Z_{\mathrm{a}}\right)$ a drought are computed for different Sc-PDSI $i$ intensities and different time periods (1, 3, and 6 months in our study).

\section{The second step}

The next step is assigning values to the CAFEC precipitation $\left(\hat{P}_{i}\right)$ in Eq. (1) since the balance of the demand and supply at the level of soil moisture is solved only at the end of the month. Once this balance reaches a deficit of water, the anomaly is reproduced at the level of the drought indicator in the next month. So, in order to supply the model with precipitations needed to recover the drought at the time when this anomaly happens, the values of CAFEC precipitations $\left(\hat{P}_{i}\right)$ were regressed against Sc-PDSI ${ }_{i-1}$ for each month during a drought. In order to solve this relation for different time periods (1-, 3-, and 6-month periods) $\hat{P}_{i}$ is linearly regressed
Table 1. Cumulative frequency, severity classes, and SC-PDSI values in the Carpathian region.

\begin{tabular}{rrr}
\hline $\begin{array}{r}\text { Cumulative } \\
\text { frequency (\%) }\end{array}$ & Severity classes & Sc-PDSI value \\
\hline 2.4 & Extremely wet & 4 or more \\
4.1 & Severe wet & $3.00-3.99$ \\
7.4 & Moderately wet & $2.00-2.99$ \\
11.6 & Slightly wet & $1.00-1.99$ \\
7.2 & Incipient wet spell & $0.50-0.99$ \\
17.3 & Near normal & $0.49--0.49$ \\
9.1 & Incipient dry spell & $-0.50--0.99$ \\
16.7 & Slightly dry & $-1.00--1.99$ \\
12.5 & Moderately dry & $-2.00--2.99$ \\
7.6 & Severely dry & $-3.00--3.99$ \\
4.0 & Extremely dry & -4 or less \\
\hline
\end{tabular}

against $\mathrm{Sc}^{-P_{D S I}}$ at time $i-1, i-3$ and $i-6$. The new $\hat{P}_{i}$ can be called the CAFEC precipitation regressed, matching the time (month) when the drought indicator registers the drought event.

\section{The third step}

In the third step, the precipitation needed to end or ameliorate the drought is computed as in Eq. (1), using both the moisture anomaly index needed to end $\left(Z_{\mathrm{e}}\right)$ or ameliorate $\left(Z_{\mathrm{a}}\right)$ the drought, as well as the regressed CAFEC.

\subsubsection{Probability calculation}

The climatological probability of receiving the amount of precipitation needed to end and ameliorate the drought was calculated using the gamma distribution. Gamma distribution has been frequently used in literature to represent precipitation (Thom, 1966; Wilks, 1990, 1995; Oeztuerk, 1981) due to the advantage that it excludes negative values, being bounded on the left at zero (Thom, 1966; Wilks, 1995). Analysis of rainfall data strongly depends on its distribution pattern (Sharma et al., 2010). This is especially important as gamma distribution is positively skewed and represents an advantage as it mimics the actual rainfall distributions for many geographical areas (Ananthakrishnan et al., 1989). Also it provides a flexible representation of a variety of rainfall regimes while utilizing only two parameters, the shape and the scale (Wilks, 1990).

The calculations were performed separately for each month and each location (grid point) on the basis of the entire 50 years of available data (1961-2010). Input data were the computed precipitation needed to end or ameliorate the drought $\left(0.1^{\circ} \times 0.1^{\circ}\right.$ resolution $)$ in the next 1,3 , and 6 months and the actual gridded monthly precipitation $\left(0.1^{\circ} \times 0.1^{\circ}\right.$ resolution $)$ accumulated for the same time periods. The probability statistics should not be considered as a forecast. They represent a quantitative measure of the proba- 

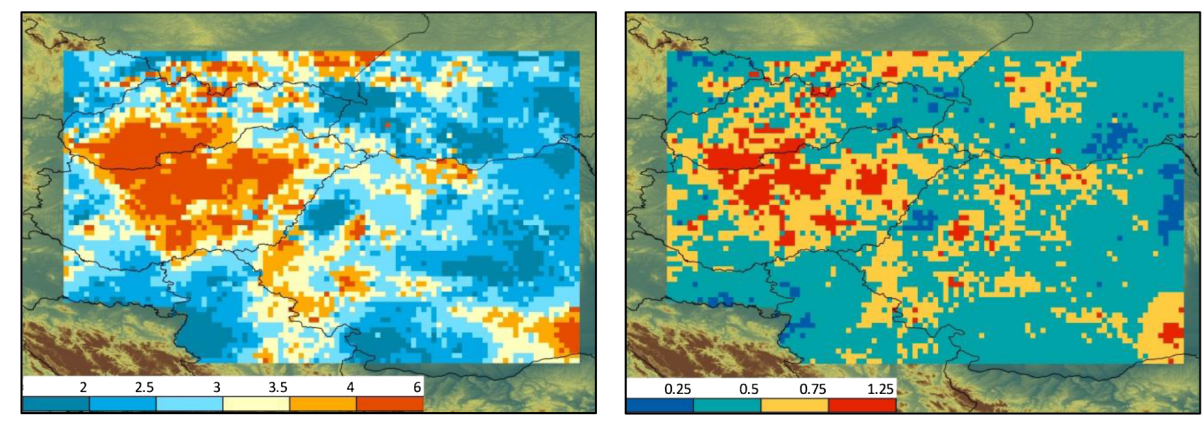

Figure 3. Average number of months per year with moderate drought (Sc-PDSI $\leq-2.0$; left) and extreme drought (Sc-PDSI $\leq-4.0$; right) in the Carpathian region (1961-2010).

bility computed on the basis of past actual precipitation data. Practically, the probability density function (PDF) of the actual precipitation data is used to find the cumulative probability (CDF) of the precipitation needed to recover from the drought for the required month and temporal scale.

All the procedures followed in the calculation of the climatological probability of recovering from a drought are based on the processes used by Oeztuerk (1981) to compute the probability distribution for precipitation. In the first step the actual precipitation data on "moving windows" of 1,3 , and 6 months are matched with the precipitation needed to recover from the drought in the next 1, 3, and 6 months. In the second step the cumulative probability (CDF) of the computed precipitation needed to end or ameliorate the drought is derived.

\section{Results}

Previous studies of drought in the Carpathian region were based on the analysis of intensity, duration and spatial extent, either at national level (e.g., Palfai, 1990; Szinell et al., 1998; Szalai, 2000; Popova et al., 2006; Trnka et al., 2009; Cheval, 2013) or at inter-regional level (e.g., Bartholy et al., 2013; Spinoni et al., 2013). Our results show that the incidence of drought in this region is rather high. During the period 1961-2010, every part of the region experienced on average between 0.5 and 6 drought months per year, (Sc-PDSI $\leq-2$, Fig. 3 left). Moreover, the incidence of extreme drought (ScPDSI $\leq-4$ ) has an occurrence of 5-45 days per year for the same time interval as shown in Fig. 3, right. When compared with other drought indicators Sc-PDSI shows good correlation with indices of long accumulation periods. The correlation between Sc-PDSI and SPI or SPEI over each grid point and for entire Carpathian region and time period (19612010) shows high values with the SPI_9 (0.85) and SPEI_9 (0.82) detecting the drought events on comparable spatial and temporal resolution and lower values with SPI_1 (0.33) and SPEI_1 (0.35) (Antofie et al., 2013).

The spatial and temporal analysis of the results for precipitations needed to recover from drought and their climatological probability is related to three levels of severity: moderate drought when $-3<$ Sc-PDSI $\leq-2$, severe drought when $-4<$ Sc-PDSI $\leq-3$, and extreme drought when Sc$\mathrm{PDSI} \leq-4$, which are evaluated on a temporal window of 1,3 , and 6 months. In order to ease the interpretation of the results with their temporal and spatial variability a review of the climatological conditions of the area related with the 0 characteristics of the Palmer drought model will be presented.

PDSI originally was designed to measure the soil moisture departure as a difference between a climatological moisture supply which in our case is the actual precipitation and the precipitation needed to maintain a normal soil moisture level (CAFEC precipitation; Palmer, 1965). In this study, other means of moisture supply such as precipitation in form of snow water equivalent are not considered. Since the regional spatial variation of precipitation in this region is mainly determined by the mountain orography and the large scale atmospheric processes (UNEP/DEWA, 2007), it is expected (in a temperate-continental climate) that moisture supply is more significant in the high altitudes while the moisture demand is higher in the low altitudes (higher rate of evapotranspiration due to higher temperatures). With increasing continental conditions from west to east and temperature decreasing from north to south, a higher moisture demand in the south and southwest, and higher moisture supplies in the northern, western and southwestern parts of the region are expected.

Based on these general climatological characteristics, the PDM will produce the highest $Z$ values (soil moisture) in the areas and for the period of the year with highest precipitation amount. The model will also indicate the most favorable period of the year for recovering from drought. The most favorable periods are the months that have the highest frequency of excess of precipitation compared to the normal. This is not necessarily the wettest month of the year but the month with the largest positive skew as the PDM is based on departures from the normal.

For both the required precipitation and the probabilities of recovery from drought a spatial pattern linked with the atmospheric circulation patterns responsible for the climate variability in the Carpathian region can be noticed. The southern 


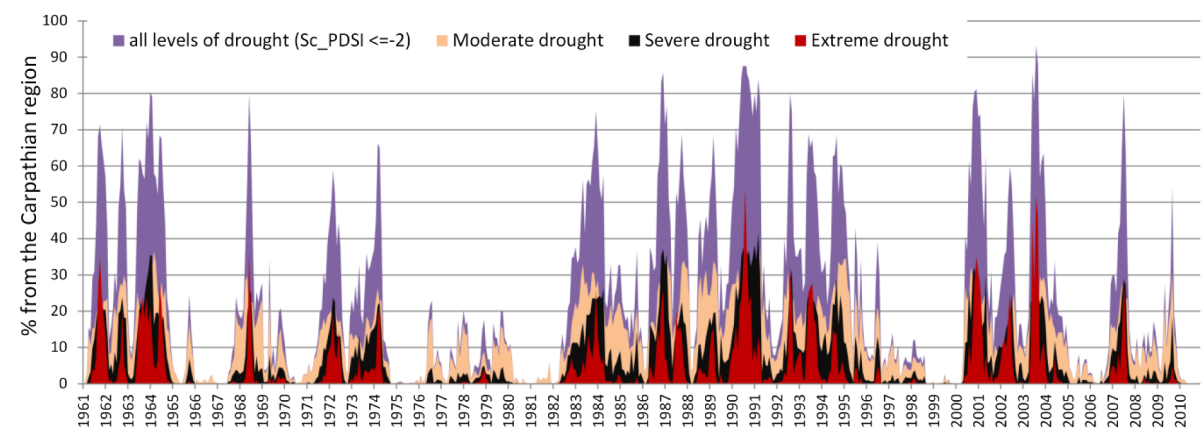

Figure 4. Incidence (\% surface of the region) of different severity levels of drought per month.

and southwestern Carpathians and the western Carpathians act like a barrier for the main sources of moisture (Mediterranean and North Atlantic air masses; Busuioc and von Storch, 1996; Busuioc, 2001). These systems are causing first, high precipitation amounts and a pronounced annual precipitation cycle, as it is the case of North Atlantic circulation in the western, northern and northwestern part of the Carpathian region. Secondly, is causing a highly variable precipitation intensity and a relatively constant distributed precipitation regime through the year (by creating a second precipitation peak in autumn), as it is the case of Mediterranean cyclones in the southwestern and southern part of the Carpathian region. The cyclonic presence and trajectories have been the subject of extensive climatological research (e.g., van Bebber, 1891; Radinovic, 1987; Katsoulis, 1998; Flocas, 1998; Maheras, 2001). Often these studies establish a connection between the advance of the cyclones from the Mediterranean area and intense precipitation events. High amounts of precipitation with genesis in the Mediterranean space (Gulf of Genoa) are produced on the cyclonal trajectory V (from the Tyrrhenian Sea to Ukraine). Most important for the Carpathian region are the trajectory Vc that crosses from west to east (the south of the Carpathian region) in spring and very rarely in summer and trajectory $\mathrm{Vb}$ (important for the western part of the Carpathian region, passing over the Pannonian Plain) towards Poland. For both trajectories, the cyclones circulate especially in autumn, winter and spring with the largest probability of occurrence in April and a secondary maximum in early autumn. The cyclone circulation diminishes and migrates southwards in DecemberJanuary, due to the intensification of both the Azores and Siberian anticyclones (Maheras, 2001).

The annual cycles of the moisture supply and demand follow a continental pattern in the Carpathian region (imposed by the North Atlantic circulation) with a maximum of supply and demand at the beginning of the summer (May-June-July) and end of summer (July-August) respectively a minimum in the winter months (December-January-February). Regardless of the annual cycles of precipitation, the months with the higher probability of substantial excess of precipitation from the normal (April-May in spring and October-November in autumn) will be related with the cyclonic presence from the Mediterranean area. Nevertheless the joined influence of the circulations moving either from the Atlantic or the Mediterranean Sea is a common characteristic of the Carpathian region (Busuioc and von Storch, 1996; Busuioc, 2001).

\subsection{Drought recovery and its temporal variability}

As shown in Fig. 4 the incidence of drought events (ScPDSI $\leq-2$ ) is most pronounced during the early years of the 1960's, 1970's and 2000's, as well as during almost the entire decade of the 1980's and 1990's and more isolated in the years 1968, 2007 and 2009. The recorded drought occurrence in the region presented through country reports at UNCCD's 1st Regional Workshop on Capacity Development to Support National Drought Management Policies for Eastern European Countries (9-11 July 2013, Bucharest) confirms the drought-prone characteristic of the region. The years with the highest drought incidence mentioned in the region are 2000, 2003, 2007 and 2012 (Holjevac et al. 2013), beginning of the 1990's (Gregorič et al., 2013), the time intervals from 19611965, 1973-1974 and also 1980's since when an increasing in the incidence of droughts it is noticed (Mateescu et al., 2013; Gregorič et al., 2013).

One of the characteristics of these drought events is the strong prevalence (\% from the area) of extreme droughts (ScPDSI $\leq-4$ ) as compared to other severity levels. This can be seen especially in the years with the highest general drought incidence over the region: 1961, 1964, 1968, 1987, 1990, 1992, 1993, 2001-2003, 2007. For these cases most of the drought events happened either in the summer period (JuneAugust) or in the winter months (December-February); for a few cases, drought occurred in October and March-April.

As shown in Table 2 for selected drought events between $200 \%$ to more than $480 \%$ of the normal 1-monthly precipitation would have been required for recovery (i.e., bringing Sc-PDSI to a level of -0.5). For a 3-month period, the percentage is reduced from $100 \%$ to almost $230 \%$ of the 3 monthly precipitation, and for a 6-month period still up to $50 \%$ above normal 6-monthly precipitation would have been required. To ameliorate a drought (i.e., reaching Sc-PDSI of 
Table 2. Percentage above the normal precipitation needed to end a drought $-\mathrm{Pp}(\%)-$ in the next 1,3 , and 6 months for the drought events with the highest incidence (\% surface from the region)

\begin{tabular}{lrrrrrrrrrr}
\hline Years & 2003 & 1990 & 1990 & 2003 & 1986 & 2003 & 1990 & 1990 & 1991 & 1990 \\
\hline Month & 8 & 8 & 7 & 9 & 12 & 6 & 9 & 6 & 3 & 10 \\
Incidence (\%) & 93.3 & 92.6 & 88.5 & 88.1 & 85.8 & 85.6 & 85.5 & 84.7 & 83.9 & 83.9 \\
1-month Pp (\%) & 414.5 & 376.9 & 625.1 & 204.1 & 368 & 228.2 & 415.7 & 374.3 & 462.5 & 482.3 \\
3-month Pp (\%) & 195.7 & 230.8 & 160.9 & 172.5 & 110.7 & 129.7 & 360.3 & 118.7 & 99 & 233.3 \\
6-month Pp (\%) & 25.2 & 57.9 & 52 & 21 & 36.3 & 34.3 & 63.1 & 49.2 & 48.2 & 62.3 \\
\hline
\end{tabular}
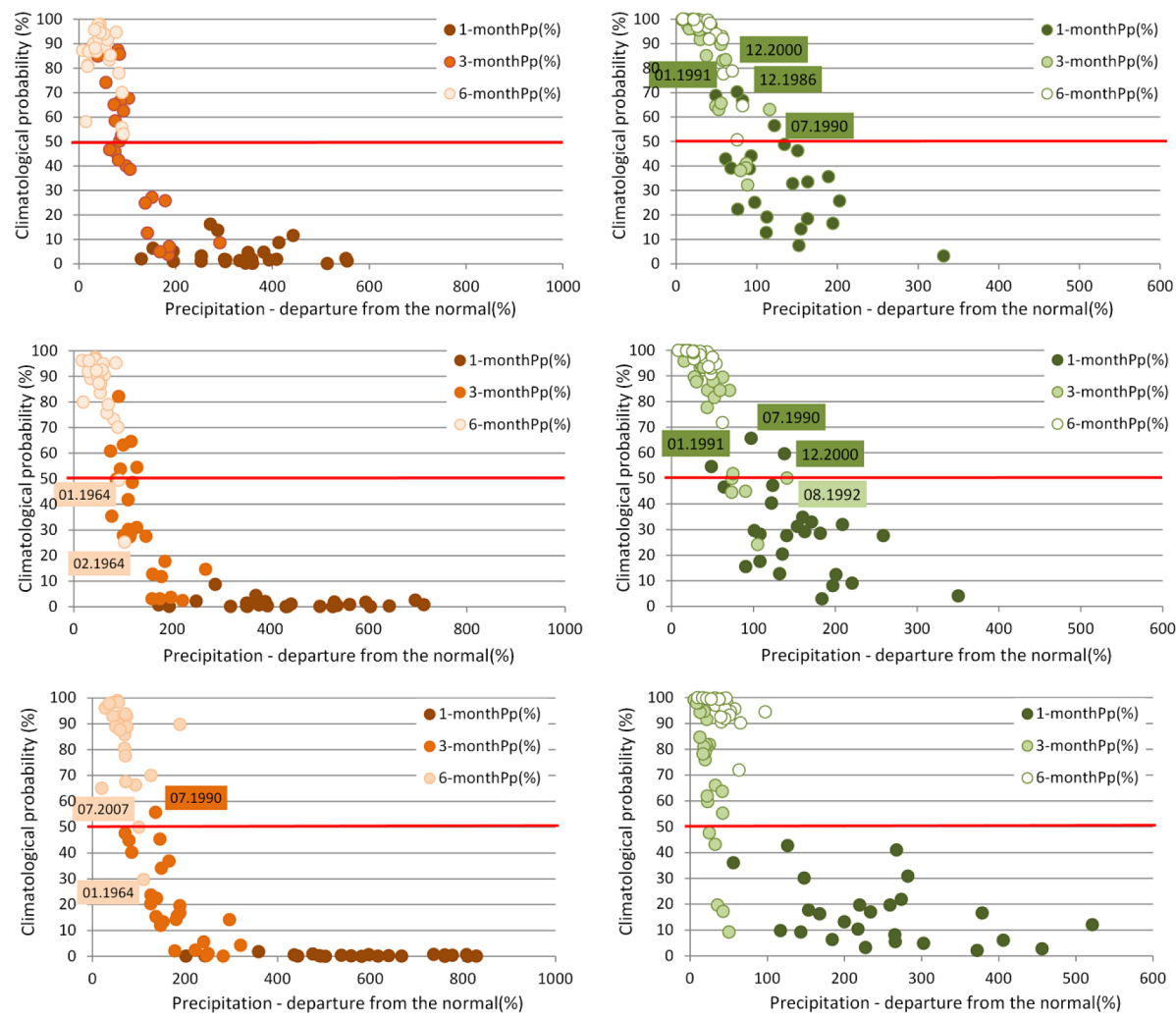

Figure 5. Probability (\%) of ending (left) or ameliorating (right) moderate (top), severe (centre) and extreme drought (bottom) events with the highest incidence in the Carpathian region in the next 1, 3, 6 months.

$\geq-2$ ) smaller amounts of precipitation would be sufficient: $70-100 \%$ above normal precipitation in a 1-month period, $30-60 \%$ in a 3-month period, and less than $20 \%$ in a 6month period.

In order to get a better idea of the climatological probabilities to recover from such droughts, we analyzed the first 25 most significant events (droughts occurring on $>75 \%$ of the area) for different drought intensity levels. Figure 5 shows the required precipitation in percent of the climatologically expected precipitation and the associated probabilities for different drought intensities and precipitation accumulation periods. It can be seen that moderate severity droughts $(-3<$ Sc-PDSI $\leq-2)$ required between 110 and $550 \%$ of the normal 1-monthly precipitation to recover from drought (top left), while for a 3-month period they ranged between 50 and $200 \%$. For a 6-month period the required precipitation is well within the climatologically expected. For the same drought cases, during the peak intensity of the drought (ScPDSI $\leq-4)$ the quantity of precipitation required increases up to approximately 8 times above normal 1 -monthly precipitation, while for a 3-month period the values reach up to $300 \%$, only for the 6-month period the precipitation required to recover from drought is close to the climatologically expected (bottom left). Severe droughts $(-4<\mathrm{Sc}-\mathrm{PDSI} \leq-3)$ would have been ended with rainfall ranging between 2 to 7 times the 1-monthly normal precipitation and approximately $100 \%$ of the 6-monthly normal precipitation (center left).

Most of these values indicate the improbability of ending or ameliorating the drought in a short period of time, as their climatological probability is (extremely) low. If we 

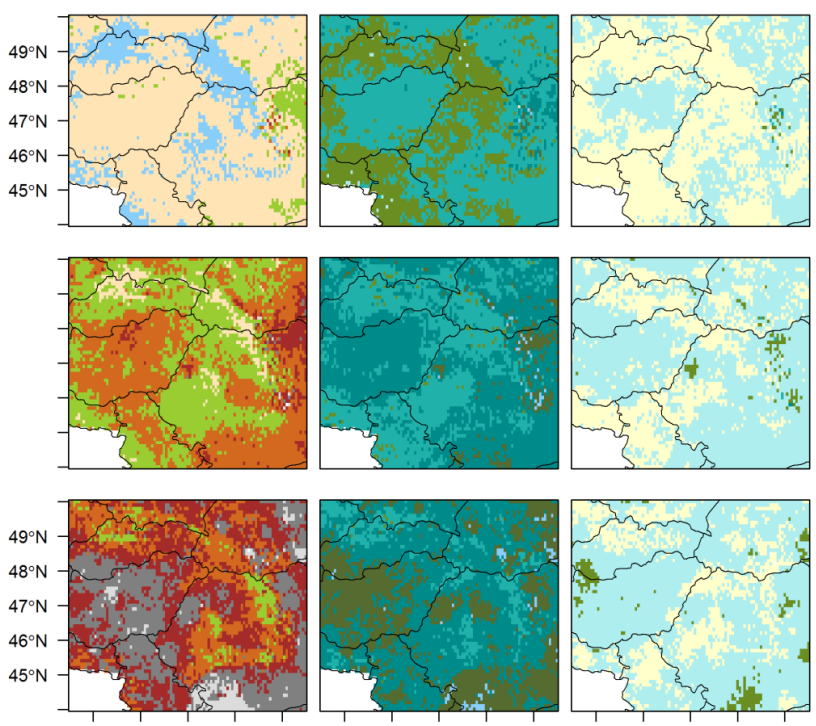

$18^{\circ} \mathrm{E} 20^{\circ} \mathrm{E} 22^{\circ} \mathrm{E} 24^{\circ} \mathrm{E} 26^{\circ} \mathrm{E}$ $18^{\circ} \mathrm{E} 20^{\circ} \mathrm{E} 22^{\circ} \mathrm{E} 24^{\circ} \mathrm{E} 26^{\circ} \mathrm{E}$ $23.8 \quad 6080100125150$ 2

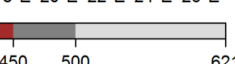

Figure 6. Percentage (\%) above the normal precipitation needed to end a (top) moderate $(-3<\mathrm{Sc}-\mathrm{PDSI} \leq-2)$, (center) severe $(-4<$ Sc-PDSI $\leq-3)$ and (bottom) extreme drought (SC-PDSI $\leq$ $-4)$ in the next month (left), next 3 months (center) and next 6 months (right) (1961-2010).

settle a limit of $50 \%$ probability, above which the amount of precipitation could be considered more likely than not (IPCC, 2007), none of the drought events could have been ended in the next month. However, a few of the moderate droughts (July 1990, December 1986, December 2000, January 1991) and of the severe droughts (July 1990, December 2000, January 1991) could have been ameliorated with 48 to $140 \%$ above the normal precipitation in 1 month (top right). On the other hand, in a 6-month period almost all drought events considered could most probably have been ended with amounts 10 to $80 \%$ above the normal precipitation (188\% for the extreme drought of April 1991). Only the severe drought from January and February 1964 and the extreme drought from July 2007 could not have been ended even in a 6-month period, making them the most excessive droughts of the studied period in the Carpathian region. Nevertheless, they could have been ameliorated with 45 to $65 \%$ above the normal 6-monthly precipitation. In a 3-month period, only one drought event of extreme intensity (July 1990, requiring $136 \%$ above the normal precipitation), 12 events of the moderate and 6 events of severe drought could have been ended with high probability. All the other events could only have been ameliorated with a range of 15 to $140 \%$ (August 1992) above the normal 3-monthly precipitation.
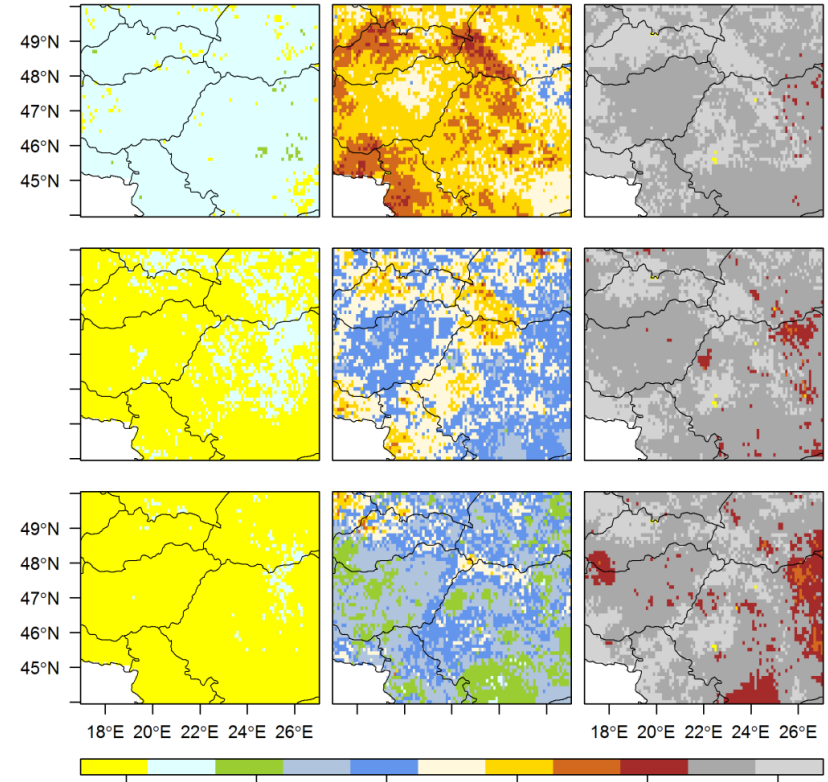

0.0

0.2

0.4

$18^{\circ} \mathrm{E} 20^{\circ} \mathrm{E} 22^{\circ} \mathrm{E} 24^{\circ} \mathrm{E} 26^{\circ} \mathrm{E}$

Figure 7. Climatological probability $(\%)$ of receiving the precipitation needed to end a (top) moderate $(-3<$ Sc-PDSI $\leq-2)$, (center) severe $(-4<$ Sc-PDSI $\leq-3)$ and (bottom) extreme drought (SCPDSI $\leq-4)$ in the next month (left), next 3 months (center) and next 6 months (right) (1961-2010).

\subsection{Drought recovery and its spatial variability}

Figure 6 presents the averaged positive deviations (in percent) from the normal precipitation needed to recover from a drought computed for the period 1961-2010. The Pannonian Basin, the Transylvanian Plateau and the external Carpathian foothills and plains in the southern and eastern part of the region require the highest relative amount of precipitation to recover from drought. In these regions, moderate droughts and extreme droughts needed between 250 and $300 \%$ (sometimes up to $600 \%$ ) above the normal precipitation to end a drought in the next month, a decrease which is noticed with increasing altitude. The topographic pattern is lost when the moisture supply is required for a larger time window. This is due to the general climate characteristics that overwrite the variability introduced by the local physical conditions. Also, the longer time intervals require less relative amounts of precipitation to recover from drought (i.e., from 20 up to 40-60\% for all the drought intensities).

Figure 7 shows the corresponding probabilities. The probability of ending or ameliorating an extreme drought (Sc$\mathrm{PDSI} \leq-4)$ or a severe drought $(-4<\mathrm{Sc}$-PDSI $\leq-3)$ in a 1 -month period is low $(<8 \%)$, showing the improbability of recovering the high intensity droughts in such a short time interval. The probability remains below $20 \%$ even for the moderate droughts. For a 3-month period, the probability of ending a drought increases from below 10 up to $40 \%$ ( for the extreme droughts), but is still unlikely $(<33 \%)$ or about as 
likely as not ending a drought (33-66\%). More likely, with a probability of $60-80 \%$ a moderate drought could be ended over almost the entire region in the 3-month time interval. Once we advance to the 6-month interval, all droughts, indifferent of their intensity level, move from likely $(>66 \%)$ to virtually certain (>99\%) to be ended.

As presented at the beginning of this section, the succession, intensity and the predominance of the cyclonic circulation may lead to a seasonal variability of the precipitation needed to recover from drought and climatological probability. The soil moisture supply and demand follow the annual cycle of precipitation and temperature (imposed by the general atmospheric circulation) but they are reflected differently at the level of the month with the highest and lowest probabilities of recovering from drought. More likely to recover from drought are the months with higher probability of substantial excess of precipitation from the normal and especially for the regions with a constant precipitation regime throughout the year. The more the precipitation regime presents a pronounced peak the more the preferred recovery moths are variable.

Corresponding to these characteristics, in almost the entire Carpathian region, the preferred months for ending a drought event are the months of April and May as in Fig. 8, corresponding to the months with the largest probability of receiving high precipitation amounts compared with the normal and a maximum activity of Mediterranean cyclones. The least preferred months for ending a drought event are the months of January and February for southern, southwestern, and northwestern regions, and October, November, and December for the northeastern part. This corresponds to the months with the largest probability of receiving low precipitation amounts compared with the normal and a minimum activity of the Mediterranean cyclones. This situation can be observed in Fig. 8 where we present the months with the highest and lowest probability for ending droughts at different intensities during the next month in Fig. 8a, the next 3 months in Fig. $8 \mathrm{~b}$ and the next 6 months in Fig. 8c.

Moderate drought events in April appear to have the highest probability for being ended in the next month. Also, severe and extreme drought events in April and May (for northern and northeastern regions) are characterized by highest probabilities of being ended in following month. The late summer (July-August) and early autumn (SeptemberOctober) drought events are ended with highest probability in the southern, western and northwestern parts of the Carpathian region as seen in the Fig. 8a, top.

In Fig. 8b top, we show that the drought events with the highest probability of being ended in 3 months are the droughts from the end of winter (January-February) in the western, southern and northwestern regions for the moderate droughts and spring droughts (April-May) in northern and northeastern regions, especially for the extreme drought events. The late autumn drought events (October-November) present the highest probability of being ended in the next 6month period as seen in Fig. 8c, top.

Concerning the lowest probabilities for ending a drought event, the worst months for ending the droughts are the winter months, corresponding to the driest period of the annual precipitation cycle and the minimum activity of the Mediterranean cyclones in the Carpathian region. This makes drought events between October (in the northern, northeastern area of the Carpathian region) and February (in the southern and eastern part of the region and Pannonian Basin) the least probable to be ended in the next month as seen in the Fig. 8a, bottom.

In Fig. $8 \mathrm{~b}$ bottom, we show that the drought events with the lowest probability of being ended in the next 3-month period are the droughts from the December in the northern and northeastern regions and autumn droughts in the other regions.

The least probable to be ended in the next 6 months are the summer droughts (June-July-August), especially in the southern and southwestern regions, while the winter droughts are the least probable to be ended in the north and northeastern part of the region as seen in Fig. 8c.

As shown, in Carpathian region, the water deficit occurs throughout the whole year. As the agriculture is an important economic sector in the Carpathian region, the drought impact could be essential. Most crops may experience water stress (deficit) at various stages in their growth cycle. The sequences of vegetative growth with their key physiological phases (i.e., crop phenology) and their sensitivity to water deficit can be used to highlight the importance of seasonal analysis of drought occurrence. Winter crops (i.e., winter wheat) are planted in Carpathian region in September through October and harvested July through August of the next year, while the spring crops (i.e., corn, spring wheat, sunflower, and potatoes) are planted April through May and harvested August through September or even October (potatoes) of the same year (UNEP/DEWA, 2007).

Early drought in the growing season (the end of autumn in October and November for winter crops and the end of spring in late April and May for spring crops) are affecting wheat germination and crop establishment (Bouaziz and Hicks, 1990). The water stress during the vegetative stages (the months of April and May for winter crops and late May and June for spring crops) may affect the leaf index development (Rickman et al., 1983). Soil water deficit increased towards harvesting (early summer for winter crops and late July or beginning of autumn in August for spring crops) is likely to produce a severe reduction in grain growth and quality which eventually cause reduction in final yields. On the other hand, it has been noted that water deficit in the maturity (anthesis) and harvesting period accelerates development (Simane et al., 1993) and significantly contribute to grain yield (Palta et al., 1994). 
a.
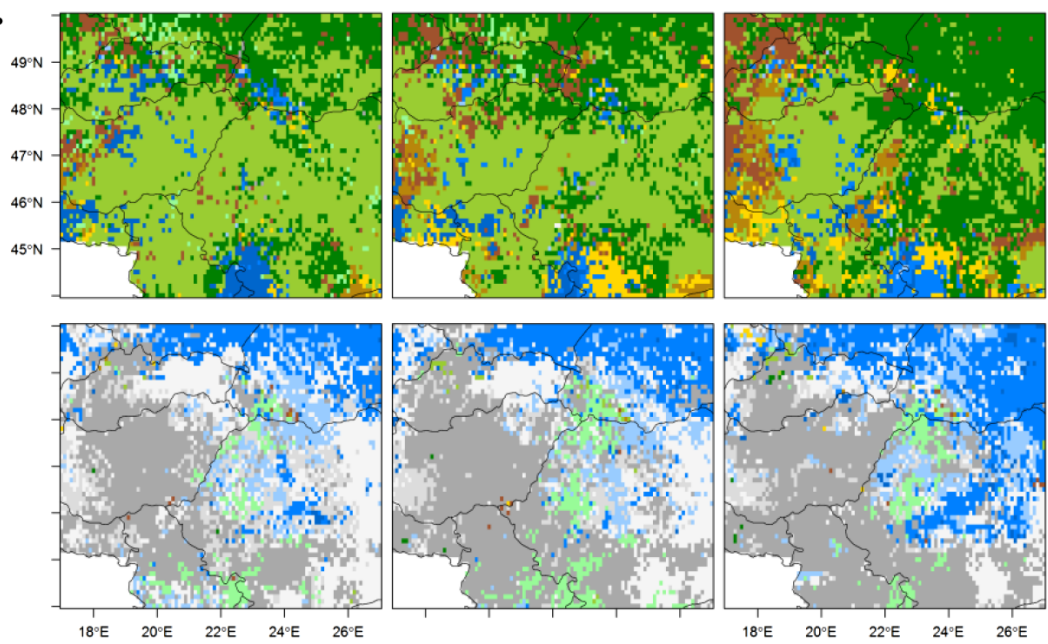

b.
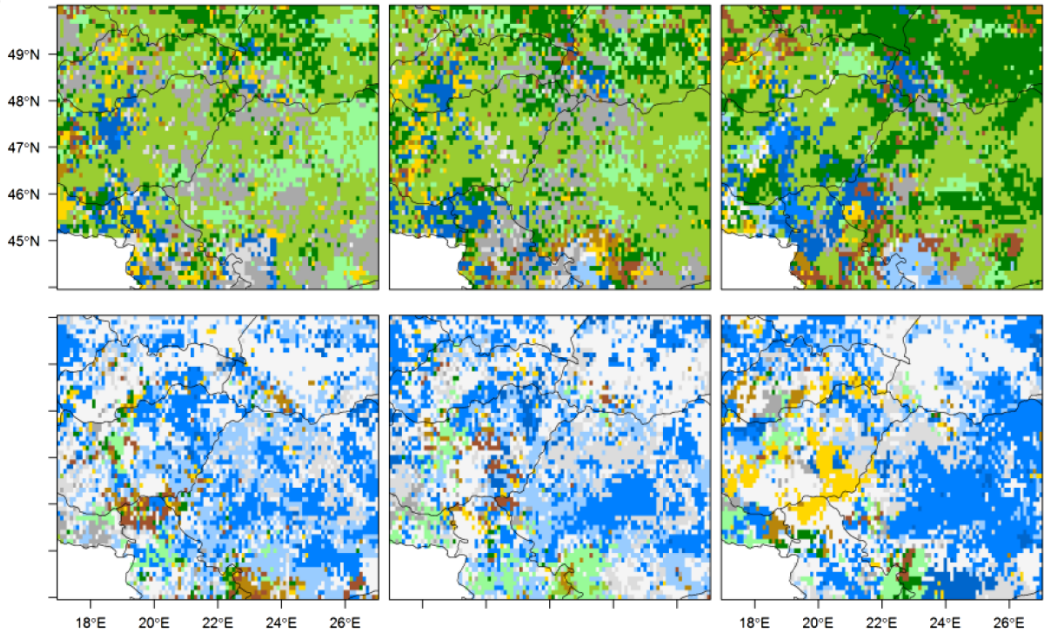

c.
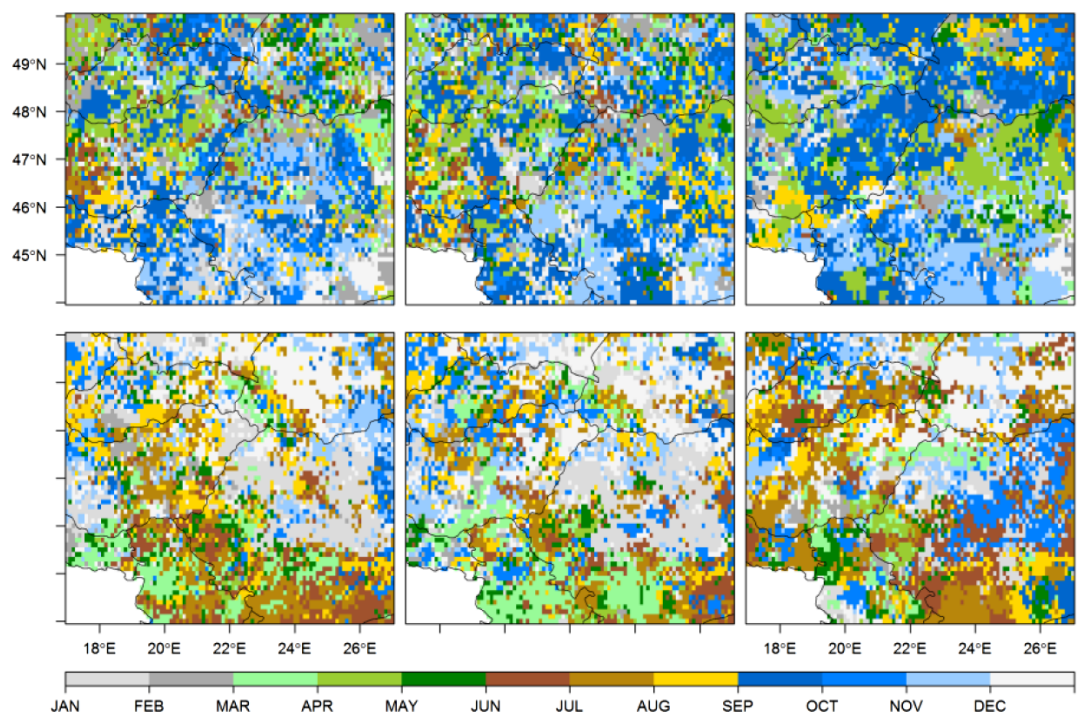

MAY

Figure 8. The months with the highest (top), and lowest (bottom) probability of having (left) a moderate drought $(-3<$ Sc-PDSI $\leq-2)$, (center) severe $(-4<$ Sc-PDSI $\leq-3)$ and (right) extreme drought $(-4 \leq$ Sc-PDSI) terminated in (a) the next month, (b) the next 3 months and (c) the next 6 months. 


\section{Conclusions}

The main characteristics of the spatial and temporal variability of the precipitation needed to end or ameliorate a drought in the Carpathian region are presented in this study. Sc-PDSI was used as a drought indicator, and the Palmer drought model was considered to calculate moisture supply and demand. The incidences of drought in the region is considerable. During the study period (1961-2010), the region experienced, on average, drought events from at least 0.5 months to 4-6 months per year for moderate droughts and less than a month per year for extreme droughts.

The amount of the precipitation needed to end a drought in the next month, reached, on average, between 200 and $480 \%$ above the normal 1-monthly and up to $50 \%$ above the 6monthly total of the normal precipitation. It was also shown that most of the drought events, irrespective of their intensity, are extremely unlikely $(<5 \%)$ to be ended in the next month.

Regionally, the Pannonian Basin, the Transylvanian Plateau and the external Carpathian foothills and plains in the southern and eastern part of the region require the highest quantity of precipitation to recover from drought and present the lowest climatological probabilities. In almost the entire Carpathian region, the preferred months for ending a drought event are the months of April and May corresponding to months with the largest probability of receiving high precipitation amounts. Often during this period of the year a connection between the cyclones from the Mediterranean area and intense precipitation events is established. The worst months for ending the droughts in the Carpathian region are the late autumn and winter months, corresponding to the driest period of the annual precipitation cycle and the minimum activity of the Mediterranean cyclones in the Carpathian region.
High precipitation amounts over the northern and northwestern part of the region are causing higher moisture supply and higher climatological probabilities to recover from drought. On the other hand for the eastern and northeastern area of the Carpathian region in October and for the southern and eastern part of the region and Pannonian Basin in February, the smallest climatological probabilities occur to recover from drought.

The early drought events for winter crops (in October and November) cause a high stress effect especially on germination and early crop establishment. On the other hand the water stress is much lower for the spring crops from April and May and for the same physiological phase due to a high cyclonic activity.

The summer droughts have a low probability to be ended, especially in the southern and southwestern regions, if in the maturity (anthesis) and harvesting periods of the crops, the water deficit can cause less damage in crop development, thereby producing even an increase in the grain yield. 


\section{Appendix A: Sc-PDSI calculation}

The computation of the self-calibrating PDSI was done in four steps: (a) computation of the soil water budget (Thornthwaite, 1948), (b) normalization with respect to demand, (c) normalization with respect to location, and (d) computation of the drought severity.

\section{A1 Computation of the soil water budget}

The computation of the soil water budget was done considering the following assumptions: the soil is divided in two layers, the AWC value is site dependent - representative of the soils type, the top layer contains $25.4 \mathrm{~mm}$ of available moisture at field capacity, the moisture stored in the soil layers changes according to the priority conditions imposed by the top layer on supply and demand. Rainfall surplus is first added to the top layer until this layer is saturated and only then it passes to the second layer while on the other hand moisture is withdrawn from the top layer first, before removing from the second soil layer.

Following these rules eight hydrological parameters of the water balance are computed: the actual evapotranspiration (ET), the soil water recharge $(R)$, the runoff $(\mathrm{RO})$, the water loss from the soil $(L)$ and their potential values used in the calculation of Palmer's constants to define the Climatically Appropriate for Existing Conditions (CAFEC) precipitation. The potential evapotranspiration was computed using the Thorntwaite formula while the other potential parameters are computed as follows (Weber and Nkemdirim, 1998): the potential recharge (PR) is the amount of moisture required to bring the soil moisture up to filed capacity (AWC minus the total amount of moisture stored in both soil layers), the potential loss (PL) is the moisture that could be lost from the soil if precipitation is zero for the month and the potential runoff (PRO) is defined as total AWC minus the potential recharge (PR). Dividing the mean actual quantity by the mean potential quantity, coefficients defining the usual climate for a specific location were obtained (for evapotranspiration $-\alpha$, recharge $-\beta$, runoff $-\gamma$, and loss $-\delta$ ) as in Eq. (A2). The four coefficients are determined for each of the 12 months. The mean of the actual and potential quantities were computed over a baseline equal to the data period available (1961-2010).

\section{A2 Normalization with respect to demand}

Normalization with respect to demand (or moisture departure for the month $-D$ ) was calculated by subtracting from the normal precipitation the amount of the precipitation needed to maintain a normal soil moisture level (CAFEC precipitation $-\hat{P}$, computed from the potential values of the water balance and their coefficients):

$D=P-\hat{P}=P-\left(\alpha_{i} \mathrm{PE}+\beta_{i} \mathrm{PR}+\gamma_{i} \mathrm{PRO} Z \delta_{i} \mathrm{PL}\right)$,

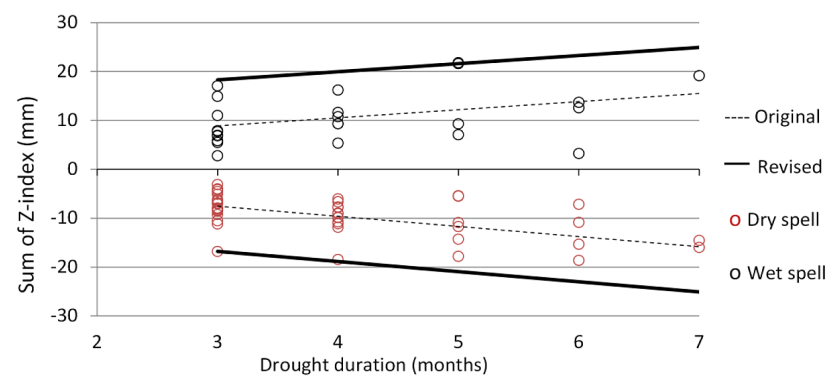

Figure A1. Accumulated z-index (mm) versus duration (months) with the intercept of the most extreme drought/wet spell.

where $D$ is the moisture departure for the month, $P$ the actual precipitation, $\hat{P}=$ CAFEC precipitation, and $\alpha, \beta, \gamma, \delta=$ water-balance coefficients computed as follows:

$\alpha=\overline{\mathrm{ET}}_{i} / \overline{\mathrm{PE}}_{i}, \beta=\bar{R}_{i} / \overline{\mathrm{PR}}_{i}$

$\gamma=\overline{\mathrm{RO}}_{i} / \overline{\mathrm{PRO}}_{i}, \delta=\bar{L}_{i} / \overline{\mathrm{PL}}_{i}$,

where ET, R, RO, $L$ are the evapotranspiration, recharge, runoff, and soil moisture loss. $\overline{\mathrm{PE}}, \overline{\mathrm{PR}}, \overline{\mathrm{PRO}}, \overline{\mathrm{PL}}$ are their potential values, the bars indicate the average value and $i$ ranges over the months of the year.

\section{A3 Normalization with respect to location}

This was done by converting the moisture departure for the month $(D)$ into an indicator of moisture anomaly $\left(Z_{i}\right)$ by multiplying the moisture departure with a climatic characteristic coefficient $(K)$. This is the point where the Sc-PDSI becomes different from the PDSI. The purpose of the climatic characteristic, $K$, is to adjust the value of PDSI according to the tails of its distribution in order to allow for an accurate comparison of PDSI values over time and space. Practically, the values of every location (pixel in this case) and each value of $\operatorname{PDSI}_{i}$ were weighted according to the 2 nd and 98th percentile of the PDSI and compared with the expected -4.0 and +4.0 calibration:

$K=\left[\begin{array}{cc}\frac{-4.0}{\mathrm{PDSI}_{2 \mathrm{nd}}}, & \text { if } D<0 \\ \frac{4.0}{\mathrm{PDSI}_{98 \mathrm{th}}} \tilde{K}, & \text { if } D \geq 0\end{array}\right]$,

where PDSI $_{2 n d}$ and PDSI 98 th are the 2nd and 98th percentile of the PDSI distribution computed using $K^{\prime}$ :

$K^{\prime}{ }_{i}=1.5 \log _{10}\left[\left(\frac{\overline{P E}+\bar{R}+\overline{R O}}{\bar{P}+\bar{L}}+2.8\right) \bar{D}^{-1}\right]+0.5$,

where $\bar{D}=$ average absolute value of the moisture departure and $\overline{\mathrm{PE}}, \bar{R}, \overline{\mathrm{RO}}, \bar{P}, \bar{L}$ are the parameters of water balance 

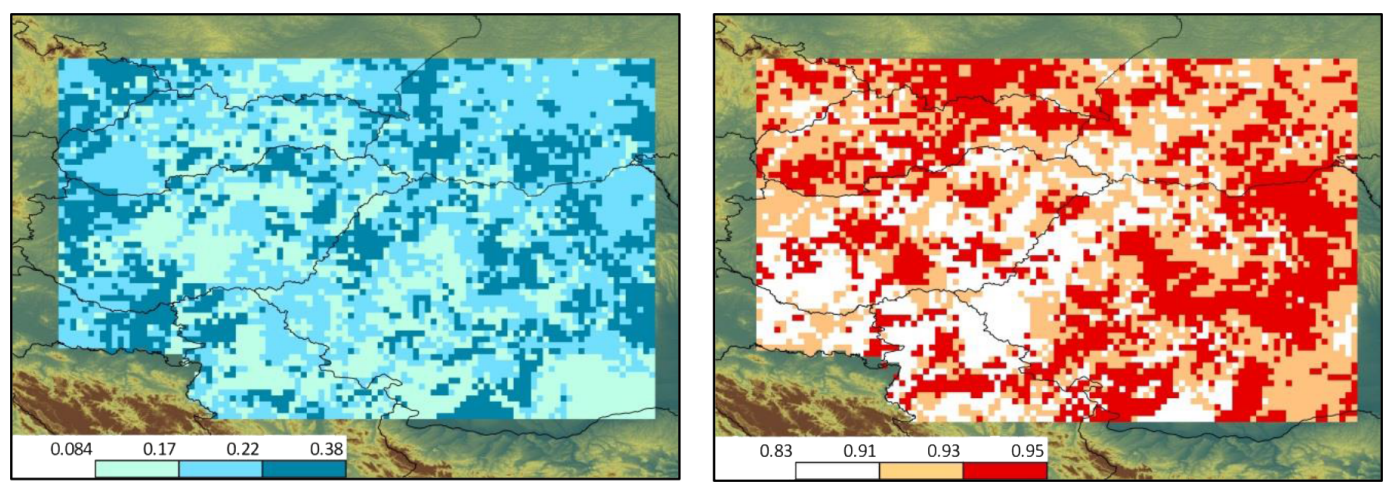

Figure A2. Duration factors $p$ (left) and $q$ (right) for dry cases in the Carpathian region (1961-2010).

values of evapotranspiration, recharge, runoff, precipitation and loss.

Using the climate characteristic coefficient $(K)$ and the moisture departure $(D)$ for the month $i$, the moisture anomaly index is computed as follows:

$Z_{i}=D_{i} \cdot K_{i}$

\section{A4 Computation of drought severity}

Once $Z$ is computed for the month $i$, the computation of the drought severity begins by relating the previous month's $\mathrm{PDSI}_{i-1}$ with the current moisture anomaly $Z_{i}$. The weights assigned to these two components are given by the duration factors $(p$ and $q)$ :

$\operatorname{PDSI}_{i}=p \mathrm{PDSI}_{i-1}+q Z_{i}$.

Differently from the original computation (the original PDSI is computed using the duration factors $p=0.897$ for $\operatorname{PDSI}_{i-1}$ and $q=1 / 3$ for $Z_{i}$ ) the Sc-PDSI duration factors for wet and dry spells are computed separately, as it is assumed that different locations have different sensitivities to precipitation events. These duration factors ( $p$ and $q$ ) were computed using the least squares method by fitting straight lines to the lowest (highest) $Z_{i}$ values accumulated over different lengths of time, aiming at representing most extreme dry/wet periods of various lengths. Practically the accumulated $Z_{i}$ was regressed against its duration (months) taking into account the most extreme dry/wet periods of various lengths as shown in Fig. A1.
The most extreme wet/dry period is defined, in this study, as events with duration greater or equal to 3 consecutive months and with the highest intensity of $Z_{i}$ (less/higher than $0.05 / 0.95$ percentiles of accumulated negative/positive $Z_{i}$ values are omitted). Once the intercepts of the most extreme wet/dry periods were computed, two sets of $p$ and $q$ (for dry/wet spells) were calculated as follows:

$p=(1-m /(m+b))$,

$q=C /(m+b)$,

where $m$ is the slope, $b$ the intercept of the extreme wet/dry period and $C$ is a calibration factor, in this study -4 and +4 were assigned for dry and wet spells. Finally, $P D S I_{i-1}$ and $Z_{i}$ from Eq. (A6) were added to compute the Sc-PDSI $i$, using the $p$ and $q$ as weighting factors. The obtained values shown in Fig. A2 vary between 0.85 and 0.95 for $p$ and 0.08 and 0.38 for $q$ of a dry spell. These values are very important as they are to be used in the calculation of the moisture anomaly index needed to end $\left(Z_{\mathrm{e}}\right)$ and ameliorate $\left(Z_{\mathrm{a}}\right)$ a drought. 
Acknowledgements. This study was supported, in part, by the results of the CARPATCLIM project (www.carpatclim-eu.org). We would like to acknowledge the work of (alphabetical order): Igor Antolovic, Ingeborg Auer, Oliver Bochnicek, Zita Bihari, Sorin Cheval, Natalia Gnatiuk, Johann Hiebl, Peter Kajaba, Piotr Kilar, Gabriela Ivanakova, Danuta Limanowka, Monika Lakatos, Monica Matei, Janja Milkovic, Dragan Mihic, Yurii Nabyvanets, Pavol Nejedlik, Predrag Petrovic, Robert Pyrc, Tatjana Savic, Oleg Skrynyk, Sandor Szalai, Tamás Szentimrey, Pavel Štastný, Petr Štěpánek, Radim Tolasz, and Pavel Zahradníček.

Edited by: S. Maskey

\section{References}

Adams, H. D., Maite, G. C., Greg, A. B. G., Juan, C. V., David, D. B., Chris, B. Z., Peter, A. T., and Travis, E. H.: Temperature sensitivity of drought-induced tree mortality portends increased regional die-off under global-change-type drought, P. Natl. Acad. Sci. USA, 106, 7063-7066, 2009.

Alley, W. M.: The Palmer drought severity index: Limitations and applications, J. Appl. Meteor., 23, 1100-1109, 1984.

Ananthakrishnan, R. and Soman, M. K.: Statistical distribution of daily rainfall and its association with the coefficient of variation of rainfall series, Int. J. Climatol., 9, 485-500, 1989.

Antofie T., Naumann G., Spinoni J., Weynants M., Szalai S., Szentimrey T., Bihari Z., and Vogt J.: A drought severity climatology for the Carpathian Region using Sc-PDSI, Geophysical Research Abstracts, EGU General Assembly, Vienna, Austria, 7-12 April 2013, 15, 2013

Bartholy, J., Pongracz, R., and Sabitz, J.: Analysis of drought index trends for the Carpathian Basin using regional climate model simulations, Geophysical Research Abstracts, EGU General Assembly, Vienna, Austria, 7-12 April 2013, 15, 2013.

Briffa, K. R., Jones, P. D., and Hulme, M.: Summer moisture variability across Europe, 1892-1991: an analysis based on the Palmer drought severity index, Int. J. Climatol., 14, 475-506, 1994.

Bouaziz, A. and Hicks, D. R.: Consumption of wheat seed reserves during and during and early growth as affected by soil water potential, Plant Soil, 128, 161-165, 1990.

Busuioc, A.: Large-scale mechanism, influencing the winter Romanian climate variability, in: Detecting and Modelling Regional Climate Change and Associated Impacts, edited by: Brunet, $M$. and Lopez, D., Springer-Verlag, Berlin, 333-343, 2001.

Busuioc, A. and von Storch, H.: Changes in the winter precipitation in Romania and its relation to the large-scale circulation, Tellus A, 48, 538-552, doi:10.1034/j.1600-0870.1996.t01-3-00004.x, 1996.

Cheval S., Busuioc, A., Dumitrescu, A., Birsan, M. V.: Spatiotemporal Variability of the Meteorological Drought in Romania using the Standardized Precipitation Index, Geophysical Research Abstracts, EGU General Assembly, Vienna, Austria, 7-12 April 2013, 15, 2013.

Ciais, Ph., Reichstein, M., Viovy, N., Granier, A., Ogée, J., Allard, V., Aubinet, M., Buchmann, N., Bernhofer, C., Carrara, A., Chevallier, F., De Noblet, N., Friend, A. D., Friedlingstein, P., Grünwald, T., Heinesch, B., Keronen, P., Knohl, A., Krinner, G.,
Loustau, D., Manca, G., Matteucci, G., Miglietta, F., Ourcival, J. M., Papale, D., Pilegaard, K., Rambal, S., Seufert, G., Soussana, J. F., Sanz, M. J., Schulze, E. D., Vesala, T., and Valentini, R.: Europe-wide reduction in primary productivity caused by the heat and drought in 2003, Nature, 437, 529-533, 2005.

Dai, A., Trenberth, K. E., and Karl, T. R.: Global variations in droughts and wet spells: 1900-1995, Geophys. Res. Lett., 25 , 3367-3370, doi:10.1029/98GL52511, 1998.

Dai, A.: Characteristics and trends in various forms of the Palmer Drought Severity Index (PDSI) during 1900-2008, J. Geophys. Res., 116, D12115, doi:10.1029/2010JD015541, 2011.

Dai, A., Fung, I. Y., Del Genio, A. D., and Qian, T.: A global dataset of Palmer Drought Severity Index for 1870-2002: Relationship with soil moisture and effects of surface warming, J. Hydrometeorol., 5, 1117-1130, 2004.

Gregorič, G. and Sušnik, A.,: Drought conditions and management strategies in Romania, Country Report, 1st Regional Workshop on Capacity Development to Support National Drought Management Policies for Eastern European Countries, Initiative on "Capacity Development to support National Drought Management Policy"(WMO, UNCCD, FAO and UNW-DPC), Bucharest, Romania, 9-11 July 2013.

Flocas, A. A.: Frontal depressions over the Mediterranean Sea and central southern Europe, Meìditerraneìe, 4, 43-52, 1998.

Guttman, N. B.: Comparing the Palmer Drought Index and the Standardized Precipitation Index, J. Am. Water Resour. As., 34, 113 $121,1998$.

Guttman, N. B., Wallis, J. R., and Hosking, J. R. M.: Spatial comparability of the Palmer drought severity index, Water Resour. Bull., 28, 1111-1119, 1992.

Hayes, M. J., Svoboda, M. D., Wilhite, D. A., Vanyarkho, O. V.: Monitoring the 1996 drought using the standardized precipitation index, B. Am. Meteorol. Soc., 80, 429-438, 1999.

Heinrich, G. and Gobiet, A.: The future of dry and wet spells in Europe: a comprehensive study based on the ENSEMBLES regional climate models, Int. J. Climatol., 32, 1951-1970. doi:10.1002/joc.2421, 2012.

Holjevac, M. C., Pavlovic, D., and Pandzic, K.: Drought conditions and management strategies in Croatia, Country Report, 1st Regional Workshop on Capacity Development to Support National Drought Management Policies for Eastern European Countries, Initiative on "Capacity Development to support National Drought Management Policy”(WMO, UNCCD, FAO and UNW-DPC), Bucharest, Romania, 9-11 July 2013.

IPCC: Contribution of Working Group I to the Fourth Assessment Report of the Intergovernmental Panel on Climate Change, Summary for Policymakers Climate Change 2007: The Phisical Science Basis, available at: www.ipcc.ch (last access: 19 December 2014), 2007.

ISDR, International Strategy for Disaster Reduction: Drought Risk Reduction Framework and Practices: Contributing to the Implementation of the Hyogo Framework for Action, United Nations Secretariat of the International Strategy for Disaster Reduction (UN/ISDR), Geneva, Switzerland, 197 pp., 2007.

Karl, T. R.: Some Spatial Characteristics of Drought Duration in the United States, J. Clim. Appl. Meteor., 22, 1356-1366, 1983.

Karl, T. R.: The Sensitivity of the Palmer Drought Severity Index and Palmer's Z-Index to their Calibration Coefficients Including 
Potential Evapotranspiration, J. Climate Appl. Meteor., 25, 7786, 1986a.

Karl, T. R.: The relationship of soil moisture parameterizations to subsequent seasonal and monthly mean temperature in the United States, Mon. Weather Rev., 114, 675-686, 1986 b.

Karl, T. R. and Knight, R. W.: Atlas of monthly Palmer hydrological drought indices (1931-1983) for the contiguous United States, Historical Climatology Series 3-7, Asheville: National Oceanic and Atmospheric Administration, National Climatic Data Center, 217 pp., 1985.

Karl, T. R., Knight, R. W., Ezell, D. S., and Quinlan, F. T.: Probabilities and precipitation required to end/ameliorate droughts, Historical Climatology Series 3-16, Asheville: National Oceanic and Atmospheric Administration, National Climatic Data Center, 315 pp., 1986.

Karl, T., Quinlan, F., and Ezel, D. S.: Drought termination and amelioration: its climatological probability, J. Clim. Appl. Meteor., 26, 1198-1209, 1987.

Katsoulis, B. D., Makrogiannis, T. D., and Goutsidou, Y. A.: Monthly anticyclonicity in southern Europe and the Mediterranean region, Theor. Appl. Climatol., 59, 51-59, 1998.

Linares, J. C. and Camarero, J. J.: From pattern to process: linking intrinsic water-use efficiency to drought-induced forest decline, Glob. Change Biol., 18, 1000-1015, 2011.

Lloyd-Hughes, B. and Saunders, M. A.: A drought climatology for Europe, Int. J. Climatol., 22, 1571-1592, 2002.

Maheras, P., Flocas, H. A., Patrikas, I., and Anagnostopoulou, C.: A 40 year objective analysis of surface cyclones in the Mediteranean region: Spatial and temporal distribution, Int. J. Climatol., 21, 359-367, 2001.

Martínez-Villalta, J., López, B. C., Adell, N., Badiella, L., and Ninyerola M.: Twentieth century increase of Scots pine radial growth in NE Spain shows strong climate interactions, Glob. Change Biol., 14, 2868-2881, 2008.

Mateescu, E., Smarandache, M., Jeler, N., and Apostol, V.: Drought conditions and management strategies in Romania, Country Report, 1st Regional Workshop on Capacity Development to Support National Drought Management Policies for Eastern European Countries, Initiative on "Capacity Development to support National Drought Management Policy”(WMO, UNCCD, FAO and UNW-DPC), Bucharest, Romania, 9-11 July 2013.

McGuire, A. D., Ruess, R. W., Lloyd, A., Yarie, J., Clein, J. C., and Juday, G. P.: Vulnerability of white spruce tree growth in interior Alaska in response to climate variability: dendro-chronological, demographic, and experimental perspectives, Can. J. Forest Res., 40, 1197-1209, 2010.

McKee, T. B., Doesken, N. J., and Kleist, J.: The relationship of drought frequency and duration of time scales, 8th Conference on Applied Climatology, Am. Meteorol. Soc., Anaheim, CA, USA, 17-23 January 1993, 179-186, 1993.

Oeztuerk, A.: On the Study of a Probability Distribution for Precipitation Totals, J. Appl. Meteorol., 20, 1499-1505, 1981.

Palfai, I.: Description and forecasting of droughts in Hungary, Proc. of 14th Congress on Irrigation and Drainage (ICID), Rio de Janario, Brasil, 30 April-4 May 1990, 151-158, 1990.

Palta, J. A., Kobata, T., Turner, N. C., and Fillery, I. R.: Remobilization of carbon and nitrogen in wheat as influenced by postanthesis water deficits, Crop Sci., 34, 118-124, 1994.
Palmer, W. C.: Meteorological drought, US Department of Commerce, Weather Bureau Research Paper, 45, 58 pp., 1965.

Popova, Z., Kercheva, M., and Pereira L. S.: Validation of the FAO methodology for computing ETo with limited data. Application to south Bulgaria, Irrig. Drain., 55, 201-215, 2006.

Radinovic, D.: Mediterranean Cyclones and their Influence on the Weather and Climate, WMO Programme on Short and Medium Range Weather Prediction Research (PSMP), WMO Sofia, 24, 131 pp., 1987.

Rebetez, M., Dupont, O., and Giroud, M.: Heat and drought 2003 in Europe: A climate synthesis, Ann. Forest Sci., 63, 569-577, 2006.

Rickman, R. W., Klepper, B. L., and Peterson, C. M.: Time distribution for describing appearance of specific culms of winter wheat, Agron. J., 75, 551-556, 1983.

Sharma, M. A. and Singh, J. B.: Use of Probability Distribution in Rainfall Analysis, New York Sci. J., 23, 40-49, 2010.

Spinoni, J., Antofie, T., Barbosa, P., Bihari, Z., Lakatos, M., Szalai, S., Szentimrey, T., and Vogt, J.: An overview of drought events in the Carpathian Region in 1961-2010, Adv. Sci. Res., 10, 21-32, doi:10.5194/asr-10-21-2013, 2013.

Szalai, S., Szinell, C. S., and Zoboki, J.: Drought monitoring in Hungary, in: Early warning systems for drought preparedness and drought management, World Meteorological Organization, Lisboa, 182-199, 2000.

Szinell, C., Bussay, A., and Szentimrey, T.: Drought Tendencies in Hungary, Int. J. Climat., 18, 1479-1491, 1998.

Simane, B., Peacock, J. M., and Struik, P. C.: Differences in development and growth rate among drought-resistant and susceptible cultivars of durum wheat (Triticum turgidum L. var. durum), Plant Soil, 157, 155-166, 1993.

Thom, H. C. S.: Some Methods of Climatological Analysis, WMO Technical note 81 , Secretariat of the WMO, Geneva, Switzerland, 53 pp., 1966.

Thornthwaite, C. W.: An approach toward a rational classification of climate, Geogr. Rev., 38, 55-94, 1948.

Toth, G. and Weynants, M.: Multiscale thematic soil water database, Deliverable 4.4 of MyWater project (call: FP7-SPA.2010.1.1-04; contract No: 263188), 2012.

Trnka, M., Dubrovský, M., Svoboda, M., Semerádová, D., Hayes, M., Žalud, Z., and Wilhite, D.: Developing a regional drought climatology for the Czech Republic, Int. J. Climatol., 29, 863883, doi:10.1002/joc.1745, 2009.

UNEP/DEWA: Carpathian Environment Outlook (KEO) Report 2007, Genève, 2007.

van Bebber, W.: Die Zugstrassen der barometrischen Minima, Meteorol. Z., 8, 361-366, 1891 (in German).

van der Schrier, G., Briffa, K. R., Jones, P. D., and Osborn, T. J.: Summer moisture variability across Europe, J. Clim., 19, 2818 2834, doi:10.1175/JCLI3734.1, 2006.

van der Schrier, G., Efthymiadis, D., Briffa, K. R., and Jones, P. D.: European alpine moisture variability 1800-2003, Int. J. Climatol., 27, 415-427, 2007.

Vicente-Serrano, S. M., Beguería, S., López-Moreno, J. I., Angulo, M., and El Kenawy, A.: A new global $0.5^{\circ}$ gridded dataset (1901-2006) of a multiscalar drought index: Comparison with current drought index datasets based on the Palmer Drought Severity Index, J. Hydrometeorol., 11, 1033-1043, doi:10.1175/2010JHM1224.1, 2010. 
Weber, L. and Nkemdirim, L.: Palmer's drought indices revisited, Geogr. Ann. A, 80, 153-172, 1998.

Wells N., Goddard, S., and Hayes, M. J.: A self-calibrating Palmer Drought Severity Index, J. Climate, 17, 2335-2351, 2004.

Wilks, D. S.: On the Combination of Forecast Probabilities for Consecutive Precipitation Periods, Weather Forecast., 5, 640-650, 1990.

Wilks, D. S.: Forecast verification, Statistical Methods in the Atmospheric Sciences, New York, Academic Press, p. 467, 1995.

Wilhite, D. A.: Drought as a natural hazard: Concepts and definitions, in: Drought: A Global Assessment, edited by: Wilhite, D. A., Routledge, New York, 1, 1-18, 2000.

Wilhite, D. A. and Buchanan, M.: Drought as hazard: Understanding the natural and social context, in: Drought and Water Crisis: Science, Technology, and Management Issues, edited by: Wilhite, D. A., CRC Press (Taylor and Francis), New York, 3-29, 2005.
Williams A. P., Xu, Ch., and McDowell, N. G.: Who is the new sheriff in town regulating boreal forest growth?, Environ. Res. Lett., 6, 041004, doi:10.1088/1748-9326/6/4/041004, 2011.

Wösten, J. H. M., Lilly, A., Nemes, A. and Le Bas, C.: Development and use of a database of hydraulic properties of European soils, Geoderma, 90, 169-185, 1999.

WMO, World Meteorological Organization: Drought monitoring and early warning: Concepts, progress and future challenges, WMO-No. 1006, 2006.

WMO/UNCCD/FAO/UNW-DPC: Capacity Development to Support National Drought Management Policies initiative, available at: http://www.ais.unwater.org/ais/course/view.php?id=37, last access: 29 November 2013. 